\title{
A measure for identifying substantial geographic concentrations*
}

\author{
Chris van Egeraat ${ }^{1}$, Edgar Morgenroth ${ }^{2}$, Rutger Kroes ${ }^{1}$, Declan Curran ${ }^{3}$, Justin Gleeson ${ }^{1}$ \\ 1 Department of Geography, Maynooth University, Maynooth, Ireland (e-mail: chris.vanegeraat@nuim.ie, \\ rutgerkroes@gmail.com, justin.gleeson@nuim.ie) \\ 2 Economic and Social Research Institute and Trinity College, Dublin, Ireland (e-mail: edgar.morgenroth@esri.ie) \\ 3 Dublin City University Business School, Dublin, Ireland (e-mail: declan.curran@dcu.ie)
}

Received: 31 July 2015 / Accepted: 14 May 2016

\begin{abstract}
Regional industrial policy emphasizes the notion of building on existing concentrations of competitive firms. A range of measures to identify such concentrations has been put forward in the literature. These measures, however, do not identify substantial concentrations which have the best potential for further development, tend to concentrate on scale measured by employment, and are applied using data for pre-specified administrative boundaries. This paper presents a new concentration index that identifies substantial concentrations and utilizes information on both the number and size of plants. It also proposes a method for generating relevant industry-specific spatial units.
\end{abstract}

JEL classification: C43, R12

Key words: Geographical concentration, industrial specialization, agglomeration, methodology, Ireland

\section{Introduction}

Since the 1970s regional industrial policy has been inspired by a range of territorial production concepts including Italianate 'neo-Marshallian industrial districts' (Brusco 1989), Porterian 'clusters' (Porter 1990), regional sectoral 'systems of innovation' (Malerba 2003; Asheim 2005) and, more recently, regional 'business ecosystems'. These concepts rest on insights from multiple disciplines and theoretical approaches, including classical location and agglomeration theory, institutional economics, socio-economic approaches and evolutionary economic geography. These territorial production concepts tend to incorporate a sectoral dimension in that they point to the benefits of geographically concentrated groupings of firms in the same or related industries.

Geographical concentration of competitive firms in specific industries is generally believed to provide advantages to the firms involved, as well as setting in motion cumulative processes

\footnotetext{
* This article partly draws on research funded by InterTradeIreland. We wish to thank David Rigby, UCLA, and three anonymous referees for helpful comments.
} 
that will lead to the further development of these concentrations in specific areas. At the same time, the growing competitiveness of these existing concentrations will impede the development of similar industries in other areas. Regional industrial policy therefore often emphasizes the notion of building on existing concentrations of competitive firms.

Much of the literature dealing with these territorial production concepts hardly addresses the question of what counts as a concentration in geographical terms. As a number of authors have noted, much work almost entirely sidesteps this issue (Phelps 1992, 2004; Martin and Sunley 2003; Phelps and Ozawa 2003)

When concentration is addressed and analysed, its identification is often based on geographical concentration and industrial specialization indices. Geographical industrial concentration can be defined as the extent to which employment in a particular industry is concentrated in a small number of localities or regions. Commonly used measures include the locational Gini, the Herfindahl-Hirschman index, the Maurel-Sedillot (MS) index (Maurel and Sedillot 1999) and the decomposable Theil index (Bickenbach et al. 2013). These indices provide measures of the overall level of geographical concentration of an industry. They provide, however, no direct insight into the importance of individual concentrations. For this, measures of regional industrial specialization such as the Krugman dissimilarity index, the Gini coefficient and the Herfindahl-Hirschman index for specialization or the simple location quotient are commonly utilized.

This article makes a case for a new measure for, and method of, identifying individual industrial concentrations. The extant measures of industrial specialization have a number of significant drawbacks when used to inform regional industrial policy-making and planning. First, most importantly, the current measures for industrial specialization do not provide a direct insight into the size or importance of individual concentrations. Industrial concentrations identified on the basis of current measures of industrial specialization can include very small concentrations (in terms of number of employees) while large concentrations are missed.

Arguably, regional industrial policy-making inspired by cluster thinking should focus on substantial concentrations. These are the concentrations which have the best potential for further development. A second shortcoming common to these measures is that they are derived solely from employment data and do not account for the number of firms, which is, at least equally important where regional industrial policy-making is partly based on an appreciation of the beneficial effects of interaction amongst multiple firms. Third, most indices do not take account of the size distribution of the concentrations. Finally, the extent of the spatial units is often prespecified to concord with administrative boundaries. As industry concentrations may incorporate parts of different administrative units, restricting the analysis to predefined administrative units is not appropriate. Applying units based on travel-to-work data (De Propris 2005) only partially resolves the issue.

This paper contributes to the literature by proposing a new concentration index that identifies substantial concentrations, and a new methodology for generating relevant, industryspecific, spatial units. The measure incorporates both the number of plants and the scale of activity measured by employment in a concentration. Furthermore, the methodology allows for the identification of industry-specific concentrations that spill across administrative boundaries by utilizing commuting-based labour fields.

The new measure is illustrated using detailed plant level data for agency-assisted firms in Ireland. This data identifies the location of plants using XY coordinates and their size is measured as total employment. A number of previous papers have considered the geographic concentration in Ireland. Morgenroth (2008) considered specialization of NUTS 3 regions over time. The analysis in this paper shows that the spatial extent of significant concentrations does not match well with that of NUTS 3 administrative boundaries. At the micro-spatial scale, analysis has focused on the differences between location patterns across sectors and the degree to 
which sectors are drawn to urban locations (Morgenroth 2009). However this analysis did not focus on groups of spatial units that could encompass substantial concentrations, which is the focus of this paper.

The paper begins by first discussing the advantages and drivers of geographical industrial concentration. This is followed by a discussion of the existing measures of geographical concentration and industrial specialization and their drawbacks. It continues with an exposition of the proposed index and methodology. The next two sections demonstrate the benefits of the methodology by applying it to Republic of Ireland data. The final section summarizes and draws conclusions for regional industrial policy-making.

\section{Geographical concentration: Advantages and derivers}

The tendency of economic activity in general, and industrial activity in particular, to concentrate in particular localities or regions has long attracted the attention of social scientists. The debate regarding the determinants of such spatial concentration and the processes involved is evolving (see McCann 1995; Martin 1999; Parr 2002; Phelps and Ozawa 2003; Brown 2010; Boschma and Fornahl 2011; Van Egeraat and Curran 2013) but, for the purposes of this paper, Marshall's original contributions are still useful for grouping the advantages identified in the recent literature. His observations on the advantages of industrial geographical concentration (Marshall $1898,1919,1930)$ tend to be summarized into a triad of external economies - a pooled market for workers with specialized skills, a growing number of increasingly specialized input suppliers and technological spillovers. The latter have become an important focus of attention, believed to underpin processes of learning and innovation (Malmberg and Maskell 1997, 2002).

In the context of open innovation models (Chesbrough 2003), inter-organizational knowledge flow is becoming an increasingly important factor. Such knowledge flow is facilitated by inter-firm networks and proximity. Proximity is deemed particularly important for tacit knowledge flow and untraded knowledge externalities. Such untraded externalities are believed to be intensified by common informal rules and conventions that, to an extent, are locally bounded. As a result, knowledge tends to become embedded in the local milieu (Malmberg 1996). Ultimately, proximity and agglomeration accelerate the diffusion of information and knowledge which leads to innovation through the development of new products, services and business models. Superior innovation performance creates a halo effect which attracts organizations and individuals to the area, setting in motion processes of cumulative causation.

Hoover (1937) refined the concept of agglomeration economies by dividing such economies into two distinct types: localization and urbanization economies. Localization economies, as identified by Marshall (1898), are advantages that firms in a single industry gain from being located in the same location while urbanization economies are advantages gained by all firms, regardless of sector, from being located together. Recently, Frenken et al. (2007) and Asheim et al. (2011) employ the concept of 'related variety', which in a sense links localization and urbanization economies. Here the advantages that firms in an industry gain from being located in the same location also benefit firms in a set of related industries (as opposed to firms in a single industry or all firms in the region).

Phelps and Ozawa (2003) show how, over time, we have witnessed different forms of agglomeration - proto-industrial, industrial, late-industrial and post-industrial agglomerations and point out that the transition between these forms involves changes in the relative importance of the types of external economies and changes in the scale or spatial extent of agglomeration. Duranton (1999) makes similar points, linking these changes to the major regulating institutions of the time - the guild in the pre-industrial era, the land market in the Industrial era and personal networks in the post-industrial era. 
It is important to note that not all instances of geographical concentration are necessarily driven by agglomeration economies. As early as the 1970s it was noted that functional (inputoutput) linkages played a limited role in the location of science-based industries (Lever 1972). In the absence of evidence for local backward linkages with specialized input suppliers or a pooled market of skilled labour, spatial concentrations are often assumed to be shaped by local spillovers. However, the existence of these spillovers is not always established (Phelps 1992; McCann 1995; Perry 2005; Orsenigo 2006; Van Egeraat and Curran 2013). In many cases of concentration, agglomeration economies may only play a limited role in driving the concentration process (see McCann 1995; Malmberg et al. 2000). In reality there are probably not many industrial concentrations where agglomeration economies are totally absent (Parr 2002). Notably, most industrial concentrations in the vicinity of urban areas are bound to benefit from at least some level of urbanization economies in the form of educational institutions, labour market pooling and infrastructure. However, these may have little impact on the process of spatial concentration or only act as 'reinforcing agglomeration economies' (Parr 2002).

In relation to the scale of geographical concentration, Phelps (1992) and Phelps and Ozawa (2003) point to the expanding geographic scale at which agglomeration has manifested itself over time. This is partly driven by changes in the relative importance of different types of external economies and changes in the geographical scale at which external economies operate. This has obvious implications for the methodology of identifying geographical concentrations and the relevant spatial unit of analysis (see Section 3).

The role and operation of external economies will also change with the evolution of individual geographical concentrations. Echoing Marshall's distinction between causes and advantages of localization (Marshall 1898), the rationale of some approaches to understanding the evolution of localized industries and clusters is that the emergence can be traced to a historical accident, leading to an initial concentration of firms. Only once a certain threshold has been reached, external economies may occur (Menzel et al. 2010). The types of external economies and their operation at least partly depend on the size (in terms of number of firms and/or workers) of geographical concentrations. The external economies, notably technological spillovers, are likely to be limited in small concentrations.

For industrial policy this means that policy-making should focus on substantial concentrations, incorporating sizeable numbers of firms and workers. From the above it is clear that even the existence of a substantial geographical industrial concentration does not guarantee that beneficial advantages and processes are in operation. Whether individual concentrations should be a target for industrial policy or whether such processes could be stimulated always requires more detailed investigation (Perry 2005). In the next sections we step back from the theoretical, functional, and policy concerns and focus on the methodology for identifying substantial geographical concentrations of industries.

\section{Geographical concentration and industrial specialization}

A large corpus of work has developed around the construction and empirical application of measures of geographical industrial concentration and related concepts. Geographical industrial concentration can be defined as the extent to which employment in a particular industry is concentrated in a small number of localities or regions. Commonly used measures include the locational Gini, the Herfindahl-Hirschman index and the Maurel and Sedillot index. All measures of geographical concentration aim to compare the geographical pattern of employment with the pattern of an aggregate, either a reference region or a uniform distribution.

Krugman (1991) proposed the locational Gini, a variant of the Gini coefficient, as a measure of spatial industrial concentration. This indicator compares the degree of concentration of an 
industry to that of a reference region, often the country as a whole. This relative measure takes values between 0 and 1 . One of the problems with this measure is that it is very sensitive to differences in the size distribution of the plants. Where employment is concentrated in a small number of plants located in a limited number of regions, the index indicates a relatively high level of spatial concentration.

The Herfindahl-Hirschman index is an absolute measure that compares the distribution of employment in a particular industry with that of a uniform distribution. The value of the index increases with the degree of concentration reaching 1 when all employment is concentrated in one region. The difference between this absolute measure and relative measures lies in the reference structures used. The two types of measures will take different values in cases where total employment is very unequally distributed across regions. Campos (2012) illustrates this with reference to the water supply industry. Because employment in water supply is relatively evenly spread across all regions, its Herfindahl-Hirschman index is low. However, because total employment is often not uniformly distributed, water supply has an average locational Gini.

These basic measures have formed the basis for more sophisticated measures of concentration. Ellison and Glaeser (1997) addressed the problem of sensitivity to differences in the size distribution of the plants by incorporating the Herfindahl index defined across plants within an industry. ${ }^{1}$ This index was further modified by Maurel and Sedillot (1999) and Devereux et al. (2004). The MS index controls for differences in the size distribution of plants and provides a relative measure of spatial concentration beyond what would be expected on the basis of concentration of employment (in terms of the distribution of employment across plants).

The formula for the MS index is:

$$
\gamma=\frac{G-H}{1-H}
$$

The first component, $G$, is a measure of raw geographic concentration, where:

$$
G=\frac{\sum_{i=1}^{M} s_{i}^{2}-\sum_{i=1}^{M} x_{i}^{2}}{1-\sum_{i=1}^{M} x_{i}^{2}}
$$

$s_{i}$ is the proportion of sector employment located in geographic area $i$ and $x_{i}$ is the proportion of aggregate industrial employment in area $i$. $M$ denotes the number of geographic areas.

Control for the size distribution of firms is obtained by adjustment for the Herfindahl index of industrial concentration (measured as the distribution of employment across plants), where:

$$
H=\sum_{j=1}^{N} Z_{j}^{2}
$$

$z_{j}$ is the share of plant $j$ in total sector employment and $N$ denotes the number of plants in the sector. The result of this adjustment is that a sector will not be regarded as spatially concentrated only because its employment is concentrated in a small number of plants. Maurel and Sedillot (1999) adopt the following classification of concentration levels: a low degree of concentration $(\gamma<0.02)$; moderately concentrated $(0.02<\gamma<0.05)$; very concentrated $(\gamma>0.05)$.

All three indices provide measures of the overall level of geographical concentration of an industry. ${ }^{2}$ They provide, however, no direct insight into the importance of individual

\footnotetext{
${ }^{1}$ The Herfindahl index is a measure of industry concentration, generally used as an indicator of competition among firms. It is defined as the sum of the squares of the market shares of each individual firm. It can range from 0 (a very large number of small firms) to 1 (a single firm).

${ }^{2}$ Duranton and Overman (2005) build on this work on the level of geographical concentration by addressing, amongst others, the issue of significance.
} 
concentrations. For this, policy-making tends to rely on measures of regional industrial specialization and dissimilarity.

Extant literature presents a range of measures of dissimilarity and specialization (Prothero 2012). Dissimilarity and similarity indices measure how similar/dissimilar a region's industrial structure is relative to that of a reference area. Popular indices in this regard include the Krugman dissimilarity index, the Gini coefficient and the Herfindahl-Hirschman index for specialization. Such indices allow for some inference in relation to specialization, in that areas with high dissimilarity values are likely to have industrial specializations.

The actual level of specialization of a specific industry in a given region can be measured with the location quotient, which measures whether the share of employment in an industry in a particular area is disproportionate relative to its share in total national employment. Formally it is defined as the share of sector $i$ in the employment in spatial unit $j$ relative to the share of sector $i$ in national employment:

$$
L Q_{i j}=\frac{E_{i j}}{E_{j}} / \frac{E_{i}}{E},
$$

where, $E=$ total employment in the national economy, $E_{i}=$ employment in industry $i$ in the national economy, $E_{j}=$ total employment in the local area and $E_{i j}=$ employment in industry $i$ in the local area.

A location quotient with a value greater than 1.0 occurs if a specific industry makes up a higher share of employee jobs in a specific area than that industry does nationally, indicating that the area has a relative specialization in that industry. Industries with a high location quotient in a region are often deemed to be geographically concentrated. The question remains how large an LQ should be before one considers it to be indicative of clustering. The often applied cut-off value of 1.25 remains arbitrary. O'Donaghue and Gleave (2004) and Duranton and Overman (2005) address this question by developing a 'standardized location quotient', which recognizes concentrations as being comprised of locations with statistically significant (rather than arbitrarily defined) LQs.

However, geographical industrial concentration and regional industrial specialization should not be conflated. Even if a specific region has a relative specialization in a specific industry, this industry can, nationally, be characterized by a low geographical concentration index, and vice versa. We therefore need to be very cautious when interpreting the results of the LQ for policy-making purposes. This is because a high LQ, or a statistically significant standardized LQ, does not necessarily point to a substantial number of employees in an industry. In fact, a small absolute number of industry employees in a region with a small number of total employees relative to the national total employees can lead to a high location quotient. In contrast, a great absolute number of industry employees in a region with a large number of total employees relative to the national total employees can lead to a low location quotient, with the danger that this group is not picked up for policy-making purposes.

One partial way around this problem is to apply a minimum threshold value of employees. Lazzeretti et al. (2008), in their analysis of creative industry clusters in Italy and Spain, apply a minimum of 250 employees. This prevents small concentrations to be identified as concentrations but it is still possible that large absolute numbers of industry employees are not identified as regional industrial concentrations.

Alternatively the location quotient can be computed by taking absolute deviations from the mean:

$$
A L Q_{i j}=\left(\frac{E_{i j}}{E_{i}}-\frac{E_{j}}{E}\right) E_{j},
$$


A

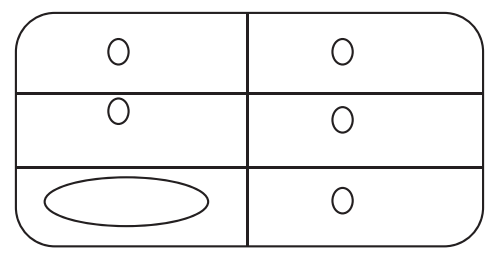

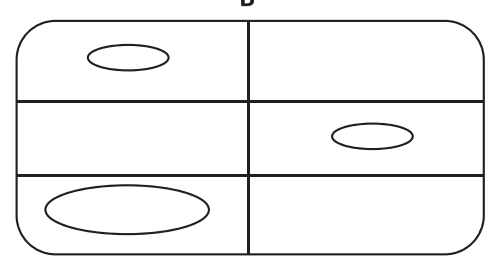

Fig. 1. Illustration of industry concentration

where values above zero indicate the local excess of employees in the industry compared to the national average. However, this absolute LQ is susceptible, in instances of regions having equal numbers of industry employees $\left(E_{i j}\right)$, to yielding a higher ALQ index to the region with the larger total employment size $\left(E_{j}\right)$. Furthermore, the absolute LQ produces similar results as the traditional LQ and the traditional LQ, combined with a threshold, is deemed to produce better results (Lazzeretti et al. 2008).

The measures for geographical concentration and industrial specialization described above have a number of significant drawbacks when used to inform regional industrial policy-making and planning. First, with the exception of the absolute LQ, neither the measures for geographical industrial concentration nor the measures for industrial specialization provide a direct insight into the relative size or importance of individual concentrations. Arguably, regional industrial policy-making inspired by cluster thinking should focus on substantial concentrations. These are the concentrations which have the best potential for further development.

A second shortcoming common to these measures is that they only use employment and do not account for the number of firms, which is, at least equally important where regional industrial policy-making is partly based on an appreciation of the beneficial effects of interaction amongst multiple firms. A focus on employment can even lead to the identification of 'one firm concentrations' based on the presence of a single very large firm (in terms of employment), while spatial units with many small firms in a particular sector may not be identified as concentrations. As discussed, this issue is addressed by the MS index but the MS index does not provide direct insight into the importance of individual concentrations. O'Donaghue and Gleave (2004) partially address this issue by controlling for the number of workers employed in firms with over 200 employees in the calculation of the standardized LQ. However, the number of firms is not directly accounted for in their measure. Firm size is also considered in the LQ-based analysis of specialization of local production systems conducted by De Propris (2005). Here, firm size is used for classification purposes; to distinguish between local production systems dominated by SMEs and those dominated by large firms. Firm size is not an element of the actual measure. ${ }^{3}$

Third, most indices do not take account of the size distribution of the concentrations. The consequence is illustrated in Figure 1. This depicts a situation where both total employment and employment in the spatial unit with the highest concentration are equal. In situation A, there is one clear industry concentration in one spatial unit and the rest of the employment is fragmented over the rest of the spatial units. In situation B, the industry overall is more concentrated in a smaller number of spatial units, which could be based on industry specific characteristics (for example the size distribution of firms in an industry). Most indices do not differentiate between these two situations but, arguably, the largest concentration is relatively more substantial in situation A than in situation B.

\footnotetext{
${ }^{3}$ The issue of firm size is also considered by Duranton and Overman (2005) in the context of a measure of geographical concentration. Establishments below a certain size threshold are excluded from the analysis. However, firm size or the number of firms is not accounted for in the actual measure. Sweeney and Feser (1998) consider geographical concentration trends by firm size class.
} 
Finally, the extent of the spatial units is usually pre-specified to concord with administrative boundaries. As Martin (2012, pp. 13-14) has observed: 'The regions and localities we study are rarely functionally meaningful economic entities, but instead are often demarcated - for data collection, administrative or political reasons - along somewhat arbitrary lines'.

As industry concentrations may incorporate parts of different administrative units, restricting the analysis to predefined administrative units is not appropriate. Utilizing administrative units also risks being susceptible to the so-called modifiable area unit problem (Openshaw 1983), where the results are sensitive to the choice of spatial unit. In the context of geographical concentration indices, this issue has been addressed by point process modelling. This involves estimating $\mathrm{K}$ functions and comparing the results against the standard of complete spatial randomness (Sweeney and Feser 1998). A similar approach is adopted by Duranton and Overman (2005), in the development of a distance-based test of localization. Marcon and Puech (2003) further refine these distance-based measures to determine the exact spatial concentration scale of industries.

However, these indices do not provide insight into the relative size or importance of individual concentrations. In the context of identifying individual concentrations the issue of arbitrary administrative boundaries tends to be addressed by using travel-to-work-data (De Propris 2005). The rationale is that these areas correspond to self-contained working and living areas that are more appropriate for identifying individual industrial concentrations. Although a step forward, the issue remains that the boundaries of these travel-to-work areas are not determined by the location patterns of individual industries.

\section{A measure for identifying substantial geographic concentrations}

In order to address the shortcomings of existing measures, we propose a concentration index (CI index) that can be used to identify substantial industrial concentrations. By substantial we mean concentrations that are large in size (in terms of firms and workers). What is considered large differs, of course, from industry to industry. We therefore let the industry-specific data determine what is, and what is not substantial. The absolute measure proposed here is not based on specialization but on disproportionately large shares of the national sector in specific areas. Furthermore, the index takes account of employment in conjunction with the number of firms, as well as the size distribution of the concentrations. Finally, we address the problem arising from working with pre-specified administrative boundaries. This begins with a description of the CI index using administrative boundaries. We then outline a methodology for dealing with the problems associated with administrative boundaries.

The starting point for the proposed measure is that an industry is defined to be overrepresented in a spatial unit when the share of industry employment and number of firms is larger than expected on the basis of a uniform distribution of employment and firms over the total country. The index applies a cut-off equal to twice the share of employment and number of firms expected from a uniform distribution.

$$
c=\left[\frac{2}{N}\right]
$$

Here, $c$ represents the cut-off and $N$ is the total number of counties in a country. The problem here is that physical sizes of the spatial units can differ. ${ }^{4}$ This means that a uniform distribution of industry employment over the surface of the country would not result in equal employment in

\footnotetext{
${ }^{4}$ Flegg and Webber (1997), in the context of using location quotients in order to derive regional input-output tables, discuss the need to account for size of the spatial units.
} 
Table 1. Two lowest and highest cut-offs based on area size

\begin{tabular}{lc}
\hline County & $C_{j}(\%)$ \\
\hline Louth & 7.18 \\
Carlow & 7.20 \\
Galway & 8.72 \\
Cork & 9.18 \\
\hline
\end{tabular}

every county. A simple solution for this problem is to use the share of a spatial unit's surface relative to the country surface multiplied by two as a spatial unit specific cut-off. If the boundaries of spatial units were drawn randomly, this approach would be an optimal solution to account for differences in spatial unit size. However, administrative boundaries are typically drawn with respect to historical settlement patterns with less populated areas having larger spatial units. Consequently, the physical size of a spatial unit is included in the formula:

$$
c_{j}=\left[\frac{2}{N}\right]^{\frac{1}{1-\left(\frac{a_{j}}{a}-\frac{1}{N}\right)}} .
$$

The relative size is incorporated as an exponent into (6) to yield an expression for $c_{j}$, in which $a$ is the surface area and $j$ is the specific spatial unit. The cut-off presented in (7) above is equal to the previous case if the size of spatial units is exactly the average size. When the spatial unit is smaller, the cut-off is lower and vice versa. Table 1 presents the effect on the cut-off for some physically small and large counties in Ireland, the subject of empirical illustration discussed in the next section.

The region specific cut-off derived in y can now form the basis of our proposed concentration indicator. As stated, the indicator uses both employment and number of firms to determine whether an industry is concentrated in a specific region.

$$
C I_{i j}=\left(\frac{E_{i j}}{c_{j} E_{i}}\right)\left(\frac{F_{i j}}{c_{j} F_{i}}\right),
$$

$C I$ represents the concentration indicator, $E$ is the employment, $F$ the number of firms and $i$ the specific industry. The separate terms for employment and number of firms are multiplied with each other. If the employment and the number of firms in an industry in a county are equal to the total national industry employment and number of firms multiplied by their respective cut-off values, the score of the $C I$ is equal to one. The multiplication of the two terms makes it possible for an industry concentration to be identified even when one of the parts of the formula has a value lower than one.

A specific element that we want to take into account is the size distribution of the concentrations as discussed in Section 3. A relatively high level of spatial concentration of a given industry should decrease the chance for any concentration to be identified as a substantial concentration based on the $\mathrm{CI}$ index. This requires the cut-off to reflect the spatial concentration of the industry, which is achieved by utilizing an adapted version of the Herfindahl-Hirschman index. ${ }^{5}$

$$
R C E_{i}=\sum_{j}^{N}\left(\frac{E_{i j}}{E_{i}}\right)^{2}, \quad R C F_{i}=\sum_{j}^{N}\left(\frac{F_{i j}}{F_{i}}\right)^{2},
$$

$R C E$ is the spatial industry concentration for employment and $R C F$ is the spatial concentration for firms, which is in both cases a value between zero and one. As with the Herfindahl index, the

\footnotetext{
${ }^{5}$ The inclusion of the adapted form to the Herfindahl-Hirschman index implicitly further controls for the size distribution of firms.
} 


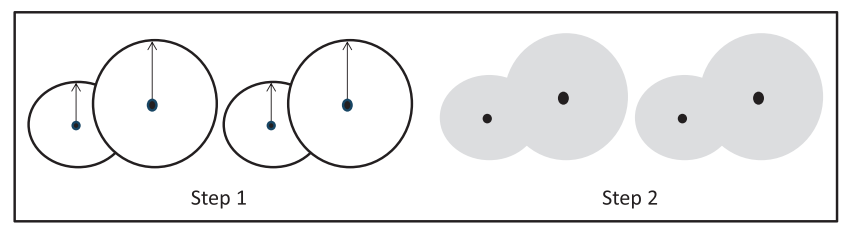

Fig. 2. Creating discrete areas of overlapping labour fields

value is based on the sum of squared shares. However, in our analysis we use the industry employment per spatial unit rather than the firm level industry employment. An outcome of one would mean that all industry employment is concentrated in one spatial unit. If the employment is equally distributed across the country, the value would approximate zero.

$$
c e_{i j}=c_{j}\left(1+R C E_{i}\right), \quad c f_{i j}=c_{j}\left(1+R C F_{i}\right),
$$

$c e$ is the cut-off value for employment in which the $R C E$ is used as a multiplier and the $c f$ is the cut-off value for firms based in the $R C F$. The result is that $c e$ and $c f$ will be doubled if the spatial concentration of an industry is one and that it is equal to $c$ if it is equal to zero. Inserting the cutoffs for employment and number of firms in the equation yields the following expression:

$$
C I_{i j}=\left(\frac{E_{i j}}{c e_{i j} E_{i}}\right)\left(\frac{F_{i j}}{c f_{i j} F_{i}}\right) .
$$

This CI index can be applied to pre-defined administrative units such as counties or regions. However, for reasons outlined, reliance on pre-defined administrative units is not optimal. Therefore a methodology is developed to determine discrete areas that better reflect the geographical shape of industry concentrations. ${ }^{6}$ The shape of the areas is determined by the geographical configuration of individual industries and area-specific travel to work flows. The areas are composed of merged labour fields of plants. The underlying logic is that firms that draw part of their workforce from the same area are potentially part of an integrated grouping.

This method involves a number of steps (see Figure 2). The first step is to identify the spatial extent of the labour fields of individual plants in an industry. The size of the labour field is determined by the travel to work area of the electoral district in which the firm is located, based on travel to work data from the CSO POWSCAR dataset, the details of which are provided in the next section. The size of the labour field is calculated as the average travel to work distance of the workers in a specific electoral district and, therefore, varies from area to area. The second step involves merging overlapping labour fields resulting in discrete areas. These areas vary in terms of spatial extent, number of firms, and employment, as well as being industry specific. The CI Index is then applied to the new set of areas to identify substantial concentrations.

One drawback of the methodology is that the resulting output of discrete areas complicates the calculation of the comprehensive CI index as outlined above. The logical adaptation of the CI index would be to use the number of concentrations instead of the number of counties in the formula. One of the complications with this lies in the large difference in the number of concentrations between industries. This results in strongly diverging cut-offs. This is not resolved and for this reason we retain a cut-off derived from county data. The control for county size can be removed, simplifying the formula for the CI index. Another drawback of the methodology is that small plants can link two or more, otherwise discrete, areas. To resolve this, the smallest 1 per cent of the firms is removed from the data set for the identification of discrete areas (but reintroduced for the calculation of the $\mathrm{CI}$ index).

\footnotetext{
${ }^{6}$ Other measures incorporating endogenous spatial scale make use of spatial weights matrices which impose a researcher determined spatial structure. See Ariba (2001) and Lafourcade and Mion (2007).
} 


\section{Data}

The new measure and methodology are applied to data for the Republic of Ireland. While other studies have used total employment as their basic yardstick for identifying geographical industry concentrations, the analysis here focuses specifically on employment in firms which are in receipt of assistance by one of the four Irish government agencies involved in enterprise promotion and development - the Industrial Development Agency, Enterprise Ireland, Údarás na Gaeltachta and Shannon Development. Hereinafter, these firms are referred to as 'agency-assisted' firms.

Employment and other data for agency-assisted firms are derived from an annual survey conducted by Forfás, the Irish government's industrial policy advisory agency. ${ }^{7}$ For 2013 the Forfás Employment Survey data covers over 8,000 firms with almost 270,000 full time employees. These firms accounted for one sixth of all employment in manufacturing and services. Agency-assisted manufacturing firms comprised about 80 per cent of all manufacturing employment and 90 per cent of total merchandise exports. Assisted services firms, while representing only seven per cent of total services employment, accounted for around 70 per cent of all services exports. Assisted firms, therefore, account for the bulk of national exports. Overall, therefore, assisted firms can be regarded as the key driver of economic development at both national and regional levels.

The database provides the following firm-level information: number of employees; address and county; electoral division in which located; NACE (Nomenclature Statistique des Activites Economiques) revision 2 code. An important feature of the data set is that it provides addresses of individual firms, which can then be geo-coded. The resulting point data are an essential input for the proposed methodology to address the problem related to working with pre-specified administrative boundaries. The commuting data used to establish the labour fields of individual plants was taken from the Place of Work, School or College - Census of Anonymised Records (POWSCAR) Census 2011. Another notable advantage of the Forfás data set is that it records the place of work of employees, in contrast to the place of living, as is the case with the Population Census data. This is an important issue in the light of the high level of Irish inter-county commuting.

The methodology outlined above has been applied at the 2-digit NACE level of industrial aggregation. Primary industries have been excluded from the analysis. A small number of additional industries have been distinguished and added to the 2-digit NACE classification including medical devices and software. These have been included because of their size and importance to the Irish economy. Their inclusion has also been driven by heuristic considerations in that extant literature provides considerable empirical knowledge about the geography of these industries in Ireland to which the output of the proposed index and methodology can be compared. The three industry groups have been constructed by combining selected 3-digit NACE categories. Very small industries, in terms of employment and firms, have been combined into a residual group of other manufacturing and services.

\section{Substantial concentrations in the Republic of Ireland}

This section examines the merits of the CI index in the empirical context of the Republic of Ireland. The analysis begins with a general discussion of the number of substantial industry concentrations identified and their location. This is followed by a more detailed analysis of its application to three industries: medical devices, pharmaceuticals and software.

Applying the CI index using pre-specified administrative county boundaries produces a total of 45 substantial concentrations. Figure 3 shows how these concentrations are co-located in a

\footnotetext{
${ }^{7}$ The authors would like to thank Forfás, now the Strategic Policy Division within the Department of Jobs, Enterprise and innovation, for allowing the researchers access to this data.
} 
small number of counties: 23 in Dublin; 12 in Cork and 4 in Galway. These are among the counties in Ireland with large urban centres and employment concentrations. In contrast, all other counties have very few concentrations, with 19 counties having no substantial concentration at all. This result was expected, since counties with relatively small numbers of firms and/or employment overall are unlikely to have substantial numbers of firms and/or employment in individual industries. Conversely, counties with relatively large numbers or firms and/or employment overall, are bound to have substantial numbers of firms and/or employment in individual industries. The main anomaly here is County Limerick which, despite of being among the four main employment concentrations in the country, has no substantial geographic industry concentration. The output generated by the CI index is significantly different from that of an analysis based on location quotients where each area is specialized in a number of industries. Figure 3 shows that the location quotient characterizes all counties as being specialized in between four and ten industries.

Table 2 and Figures 4 to 6 illustrate the application of the CI index and method on three specific industries: medical devices, pharmaceuticals and software. In Table 2 the output of the CI index applied at the county level is contrasted with the output of a simple location quotients analysis. The figures present the concentrations based on the location quotient analysis (left map), the substantial concentrations based on the CI index applied at the county level (centre map) and the substantial concentrations based on the CI index at the level of overlapping labour fields (right map).

Starting with medical devices, the location quotient analysis suggests quite extensive areas of concentration, covering nearly half the country, though not including County Cork, the county with the second highest number of employees in the industry. Applying the CI index at the county level reduces the number of counties with substantial concentrations to two, now including County Cork which was not picked up as a concentration by the location quotient analysis. The concentrations are rather coarsely defined, covering the entire area of two counties. The overlapping labour field methodology not only refines the geographical extent of the identified concentrations but also detects other concentrations around Limerick, Athlone and Dublin. This map closely expresses the empirical reality described in extant literature (Giblin 2008; Curran and Van Egeraat 2014).
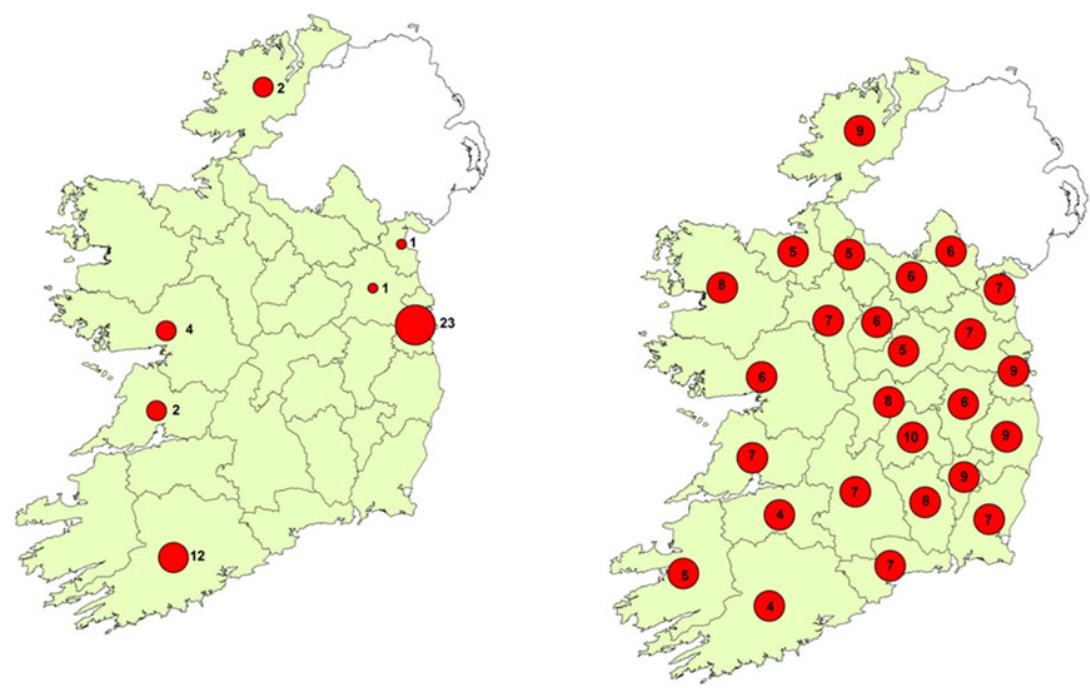

Fig. 3. Substantial industry concentrations based on CI index per county (left); industry concentrations based on LQ (right) 
Table 2. LQ and CI indices, county level, for three industries

\begin{tabular}{|c|c|c|c|c|c|c|c|c|c|c|c|c|}
\hline \multirow[b]{2}{*}{ County } & \multicolumn{4}{|c|}{ Pharmaceuticals } & \multicolumn{4}{|c|}{ Medical devices } & \multicolumn{4}{|c|}{ Software } \\
\hline & $\mathrm{LQ}^{1}$ & $\mathrm{CI}$ & Emp. & Firms & LQ & CI & Emp. & Firms & LQ & $\mathrm{CI}$ & Emp. & Firms \\
\hline Carlow & $1.7^{1}$ & 0.0 & 190 & 1 & 0.0 & 0.0 & 5 & 2 & 0.3 & 0.0 & 109 & 9 \\
\hline Cavan & 0.1 & 0.0 & 43 & 1 & 0.0 & 0.0 & 0 & 0 & 0.1 & 0.0 & 122 & 2 \\
\hline Clare & 0.8 & 0.0 & 367 & 2 & 1.0 & 0.1 & 535 & 3 & 0.4 & 0.0 & 759 & 28 \\
\hline Cork & $1.9^{1}$ & $4.6^{1}$ & 4404 & 30 & 1.1 & $1.3^{1}$ & 3044 & 11 & 0.8 & $1.0^{1}$ & 7453 & 197 \\
\hline Donegal & 0.1 & 0.0 & 56 & 2 & 0.3 & 0.0 & 138 & 1 & 1.1 & 0.1 & 1797 & 33 \\
\hline Dublin & 0.8 & $13.5^{1}$ & 5262 & 45 & 0.1 & 0.7 & 725 & 16 & $1.6^{1}$ & $34.1^{1}$ & 44138 & 683 \\
\hline Galway & 0.4 & 0.1 & 468 & 8 & $4.4^{1}$ & $7.3^{1}$ & 6365 & 27 & 0.8 & 0.2 & 3758 & 81 \\
\hline Kerry & 1.1 & 0.1 & 354 & 5 & 0.2 & 0.0 & 66 & 1 & 0.3 & 0.0 & 373 & 27 \\
\hline Kildare & 1.1 & 0.2 & 672 & 5 & 0.0 & 0.0 & 2 & 1 & 1.0 & 0.1 & 2464 & 20 \\
\hline Kilkenny & 0.0 & 0.0 & 0 & 0 & 0.0 & 0.0 & 0 & 0 & 0.1 & 0.0 & 145 & 13 \\
\hline Laoighis & 0.0 & 0.0 & 0 & 0 & 0.0 & 0.0 & 0 & 0 & 0.0 & 0.0 & 2 & 1 \\
\hline Leitrim & 0.0 & 0.0 & 0 & 0 & 0.0 & 0.0 & 0 & 0 & $1.8^{1}$ & 0.0 & 468 & 2 \\
\hline Limerick & 0.0 & 0.0 & 2 & 1 & $3.0^{1}$ & 1.0 & 2269 & 8 & 0.8 & 0.1 & 1865 & 70 \\
\hline Longford & 0.0 & 0.0 & 2 & 1 & $2.2^{1}$ & 0.1 & 372 & 3 & 0.0 & 0.0 & 20 & 3 \\
\hline Louth & 0.3 & 0.0 & 119 & 4 & 0.3 & 0.0 & 148 & 4 & 0.9 & 0.0 & 1293 & 22 \\
\hline Mayo & $2.2^{1}$ & 0.1 & 913 & 4 & $3.0^{1}$ & 0.4 & 1553 & 6 & 0.3 & 0.0 & 486 & 18 \\
\hline Meath & 0.3 & 0.0 & 101 & 3 & 0.6 & 0.0 & 249 & 1 & 0.3 & 0.0 & 396 & 11 \\
\hline Monaghan & 0.0 & 0.0 & 9 & 1 & 0.0 & 0.0 & 0 & 0 & 0.0 & 0.0 & 36 & 2 \\
\hline Offaly & 0.2 & 0.0 & 37 & 2 & $1.9^{1}$ & 0.1 & 565 & 3 & 0.0 & 0.0 & 33 & 9 \\
\hline Roscommon & $4.4^{1}$ & 0.1 & 552 & 3 & $2.0^{1}$ & 0.1 & 312 & 3 & 0.1 & 0.0 & 29 & 4 \\
\hline Sligo & $2.2^{1}$ & 0.1 & 474 & 5 & $2.6^{1}$ & 0.2 & 708 & 5 & 0.1 & 0.0 & 96 & 12 \\
\hline Tipperary & $1.9^{1}$ & 0.2 & 920 & 5 & $2.9^{1}$ & 0.2 & 1761 & 2 & 0.0 & 0.0 & 22 & 6 \\
\hline Waterford & $3.6^{1}$ & 0.6 & 1628 & 7 & $2.1^{1}$ & 0.3 & 1183 & 4 & 0.6 & 0.0 & 1054 & 33 \\
\hline Westmeath & 0.0 & 0.0 & 2 & 1 & $2.0^{1}$ & 0.2 & 774 & 5 & 1.0 & 0.0 & 1217 & 18 \\
\hline Wexford & 0.0 & 0.0 & & & $2.1^{1}$ & 0.1 & 959 & 2 & 0.1 & 0.0 & 112 & 10 \\
\hline Wicklow & $3.3^{1}$ & 0.3 & 994 & 5 & 0.6 & 0.1 & 242 & 4 & 0.2 & 0.0 & 223 & 30 \\
\hline All & & & 17,569 & 141 & & & 21,975 & 112 & & & 68,470 & 1,344 \\
\hline
\end{tabular}

Notes: ${ }^{1}$ Denote specializations $(\mathrm{LQ}$ cutoff $=1.25)$ and substantial concentrations $(\mathrm{CI})$.

Moving to the pharmaceutical industry we also observe diverging sets of industry concentrations yielded by the competing measures. Here, the location quotient analysis suggests quite extensive areas of concentration, covering one third of the country, though not including County Dublin (the county with the highest number of employees in that industry). Applying the CI

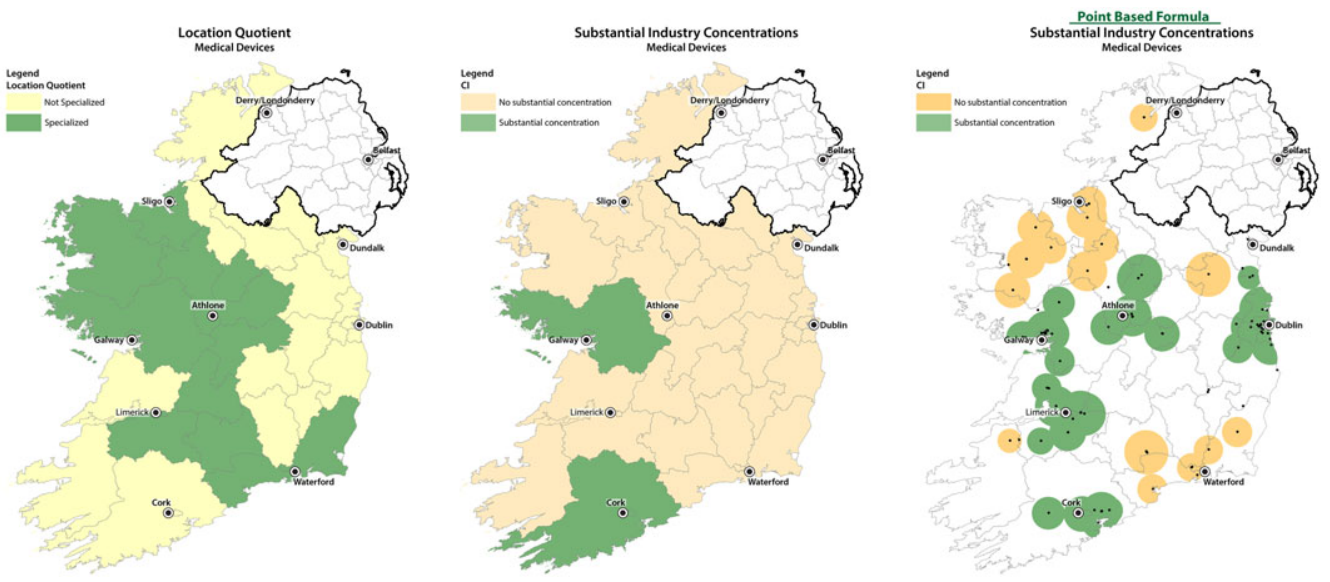

Fig. 4. Application of three methodologies to medical devices industry 

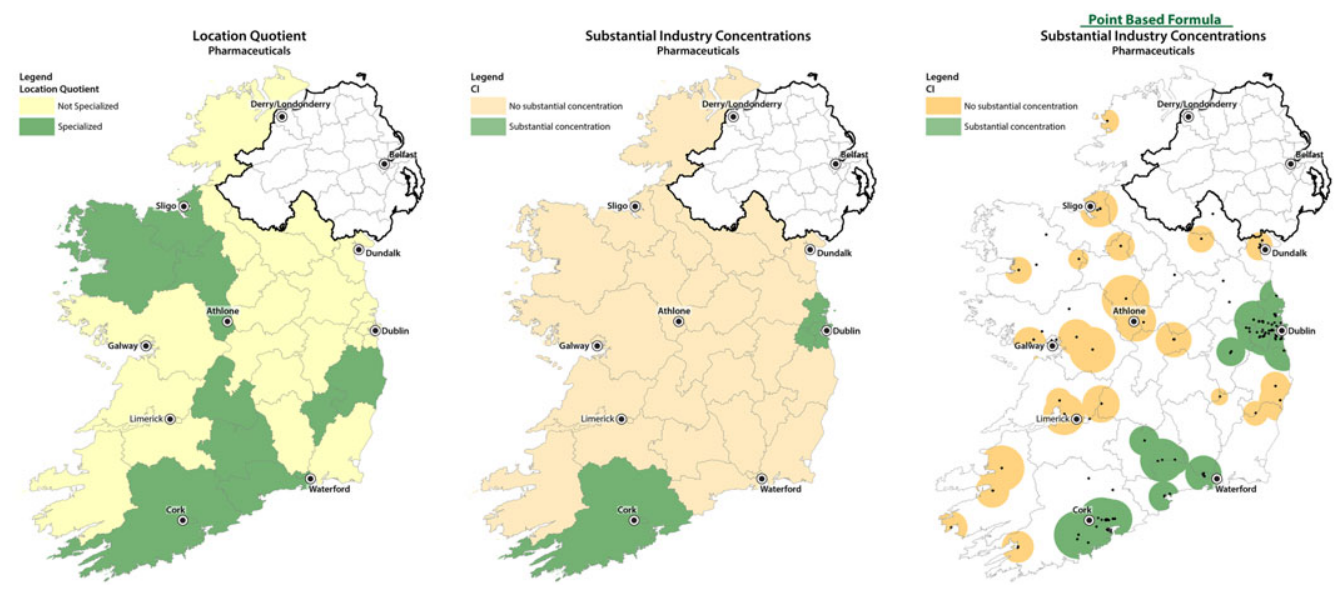

Fig. 5. Application of three methodologies to pharmaceuticals industry
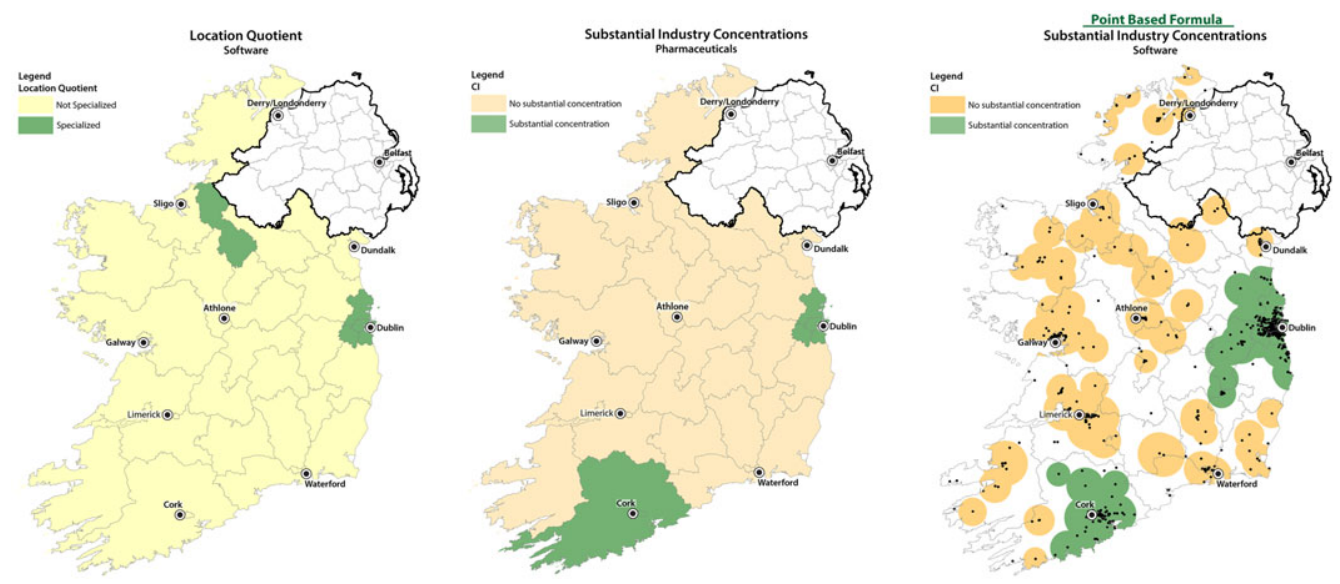

Fig. 6. Application of three methodologies to software industry

index at the county level reduces the number of substantial concentrations to Counties Dublin and Cork. Once again, the overlapping labour field methodology not only refines the geographical extent of the concentrations but also identifies an additional discrete substantial pharmaceutical concentration around Waterford. This method provides a precise depiction of the empirical reality of two discrete substantial pharmaceutical concentrations in the south of Ireland, one focused on drug substance chemical synthesis (around Cork) and one on drug product manufacturing (around Waterford) (see Van Egeraat and Curran 2014).

The analysis of the software industry again illustrates the advantage of the labour field version of the CI methodology. The location quotient analysis suggests concentrations in County Dublin and County Leitrim in the north-west, the least populous country of the country bereft of any significant urban concentration. County Leitrim's software industry 'concentration' consists of two firms employing about 468 workers. In contrast, the grouping of nearly 200 software firms in Cork, employing over 7,000 workers is not detected. This is resolved by the application of the CI index at the county level which identifies two substantial concentrations, Cork and Dublin, the counties with the two main urban centres. The output of the overlapping labour field 
method is again more refined but also suggests that the substantial concentration around Dublin is spatially more extensive, stretching into Dublin's hinterland.

The impact of taking account of the number of firms in conjunction with the scale of employment is best illustrated by the data on other industries (not presented in the table). For example in the case of vehicle manufacturing, Dublin with 208 employees in 10 firms, is characterized by a low LQ (0.2). It is however considered a substantial concentration $(\mathrm{CI}$ index $=1.8$ ). By contrast, County Limerick, with over twice the number of workers, has a low CI (0.2) partly because all workers are concentrated in a single firm.

The output for all industries is summarized in Table 3. The analysis reveals striking differences across industries with respect to their spatial configuration, with some substantial concentrations encompassing the entire country while others are regional or local. Arguably, concentrations covering most of the country should not be referred to as concentrations. In fact these are ubiquitous industries, the opposite of geographically concentrated industries. These

Table 3. Substantial industry concentrations (based on CI index and labour field methodology)

\begin{tabular}{|c|c|c|}
\hline Industry & Detail & Number \\
\hline Manufacturing of food products & Ubiquitous & 0 \\
\hline Manufacturing of Beverages & Dublin & 1 \\
\hline Manufacturing of textiles & $\begin{array}{l}\text { Dublin/Mid-East region, reaching } \\
\text { into Dundalk }\end{array}$ & 1 \\
\hline Manufacturing of wearing apparel & Dublin/Mid-East region & 1 \\
\hline $\begin{array}{l}\text { Manufacturing of wood and wood products, } \\
\text { except furniture }\end{array}$ & $\begin{array}{l}\text { Very extensive - Leinster province/ } \\
\text { West/Midlands }\end{array}$ & 0 \\
\hline Manufacture of paper and paper products & Dublin reaching into the Mid-East region & 1 \\
\hline Printing and reproduction of recorded media & Dublin & 1 \\
\hline Manufacture of chemicals and chemical products & $\begin{array}{l}\text { Dublin reaching into Midlands; } \\
\text { Cork; Limerick }\end{array}$ & 3 \\
\hline $\begin{array}{l}\text { Manufacture of basic pharmaceutical products and } \\
\text { pharmaceutical preparations }\end{array}$ & Dublin; Cork and Waterford/South East & 3 \\
\hline Manufacture of rubber and plastic products & $\begin{array}{l}\text { Midlands plus Monaghan, Dublin/ } \\
\text { Mid-East coast }\end{array}$ & 2 \\
\hline Manufacture of other non-metallic mineral products & $\begin{array}{l}\text { Almost ubiquitous except for the West } \\
\text { and South }\end{array}$ & 0 \\
\hline $\begin{array}{l}\text { Manufacture of fabricated metal products, except } \\
\text { machinery and equipment }\end{array}$ & Almost ubiquitous & 0 \\
\hline Manufacture of electrical equipment & Dublin; Limerick & 2 \\
\hline Manufacture of motor vehicles, trailers and semi-trailers & Greater Dublin & 1 \\
\hline Manufacture of furniture & $\begin{array}{l}\text { East coast including Monaghan down } \\
\text { to Waterford and Midlands region }\end{array}$ & 1 \\
\hline Manufacturing of Medical Devices & Dublin; Midlands; The West; Cork & 4 \\
\hline Repair and installation of machinery and equipment & No single substantial concentration & 0 \\
\hline Publishing activities & Greater Dublin & 1 \\
\hline $\begin{array}{l}\text { Motion picture, video and television programme } \\
\text { production, sound recording and music publishing activities }\end{array}$ & Dublin stretching into Wicklow; Galway & 2 \\
\hline Computer programming, consultancy and related activities & $\begin{array}{l}\text { Extensive concentrations Dublin/ } \\
\text { Mid-East; Cork }\end{array}$ & 2 \\
\hline Information service activities & Dublin & 1 \\
\hline $\begin{array}{l}\text { Financial services activities, except insurance and } \\
\text { pension funding }\end{array}$ & Dublin & 1 \\
\hline Activities of head offices; management consultancy activities & Dublin, stretching into Kildare & 1 \\
\hline $\begin{array}{l}\text { Architectural and engineering activities; technical testing } \\
\text { and analysis }\end{array}$ & $\begin{array}{l}\text { Dublin reaching south to Carlow and } \\
\text { into the Midlands region }\end{array}$ & 1 \\
\hline $\begin{array}{l}\text { Office administration, office support and other } \\
\text { business support activities }\end{array}$ & Dublin, reaching into the Mid-East region & 1 \\
\hline
\end{tabular}


include the more traditional industries, such as: food products; wood and wood products; other non-metallic mineral products; and fabricated metal products.

Most other industries are characterized by three or less substantial concentrations with a substantial number of single-concentration industries. All non-ubiquitous industries have a concentration encompassing Dublin. In relation to the three other main employment centres, Cork is included in substantial concentrations of four industries, Limerick in three, and Galway in two. The anomaly of Limerick, observed in the context of applying the CI index at the county level, is therefore resolved when using the labour field methodology.

Overall, the labour field methodology results in a total of 31 substantial concentrations, a reduction of 14 compared to the CI index applied to the county level. Of these concentrations, 29 encompass at least one of the main employment centres in the country. This is an even greater share than was observed in the context of the CI index applied at county level. However, due to the fact that concentrations are now crossing county boundaries, a greater number of counties are, at least partially, incorporated in substantial concentrations. The fact remains, however, that many area and counties are not linked to any substantial industry concentrations (excluding ubiquitous industries). These tend to be peripheral locations with no substantial employment centres, such as Counties Donegal, Mayo, Kerry and Leitrim as well as the peripheral areas of Counties Cork and Galway, predominantly in the west of Ireland.

\section{Conclusion}

The geographical concentration of competitive firms in specific industries is generally believed to provide advantages to the firms involved and to set in motion processes that will lead to the further development of these concentrations in specific areas. At the same time, the growing competitiveness of these existing concentrations will impede the development of similar industries in other areas. Regional industrial policy therefore tends to include the notion of building on existing concentrations of competitive firms.

The identification of existing concentrations is often based on geographical concentration and industrial specialization indices that do not provide a direct insight into the relative size or importance of individual concentrations. Arguably, regional industrial policy-making inspired by cluster thinking should focus on substantial concentrations. These are the concentrations which have the best potential for further development. Further shortcomings of existing indices include the fact that they tend not to account for the number of firms in a concentration, as well as their restriction of the analysis to pre-defined administrative units or travel-to-work areas.

This article proposes a new concentration index that can be used to identify substantial industrial concentrations. It has a number of features:

- it is not based on specialization but on disproportionately large shares of the national sector in specific areas;

- it takes account of the scale of employment in conjunction with the number of firms;

- it takes account of the size distribution of concentrations; and

- it is not reliant on pre-specified administrative boundaries but, instead creates industryspecific discrete areas, based on area-specific commuting fields of the labour force.

The measure and methodology were applied to recent data for the Republic of Ireland. The analysis illustrates the advantages of the index and methodology over existing indices. The measure only identifies substantial industrial concentrations. Compared to the output of traditional indices, the measure produces fewer concentrations that are more suitable targets for industrial 
policy. Most of these concentrations encompass the main employment centres of the country. However, the output is not simply a reflection of the general employment distribution. The analysis highlights important differences across sectors and identifies concentrations of differing spatial extent.

The analysis clearly demonstrates the advantage of the overlapping labour fields methodology over working with pre-specified administrative boundaries. It shows how many concentrations extend into neighbouring counties. For some non-core counties and areas, this identifies opportunities and targets for policy-making that could have been ignored when using more traditional indices. It also underscores the importance of co-ordinating industrial policy at the regional level. The fact remains, however, that many peripheral areas and counties are not linked to any substantial industry concentrations. This is equally informative for policy-making. It suggests that cluster type, or smart specialization type, industrial policies are less suitable or less effective in such areas. This does not mean that there are no opportunities for industrial development. Some of the ubiquitous industries provide opportunities for development. Or industrial policy may 'simply' focus on creating key framework conditions that support industries in general.

The proposed CI index and methodology have two drawbacks that may be the subject of further study. Firstly, the index and methodology may not be directly transferable to other contexts with different settlement and sectoral structures (size distribution of firms). In the context of Ireland and the specific dataset used, the methodology of overlapping labour fields does not present sufficiently discrete labour fields. To resolve this, the smallest 1 per cent of firms is removed from the data set. In other countries, depending on the settlement and sectoral structure, a smaller or larger percentage of firms may need to be removed. The other drawback, related to the overlapping labour field methodology, is that the output complicates the calculation of the comprehensive CI index. The pragmatic solution adopted means that the CI index loses some of its sophistication.

Finally, as with all indices, the CI index and methodology merely identifies substantial geographical industrial concentrations. The core of this article has sidestepped the theoretical, functional and policy concerns related to geographical concentration of industries. Based on the observed spatial configurations, we now provide some further consideration of the drivers of geographical industrial concentration, agglomeration processes, the role of the different external economies and the geographical scale at which these different external economies operate.

Extant literature has addressed the complexity of the agglomeration concept. Markusen (1996) identifies distinct structural forms of industrial districts. Focusing more on the underlying processes, Gordon and McCann (2000) distinguish three ideal typical models of processes which may underlie spatial concentration - the classical model of pure agglomeration, the industrial complex model and the social network model. The models involve different types of spatial externality. There is also an increasing appreciation of the fact that the different external economies can manifest themselves at different geographical scales (Phelps 1992, 2004; Phelps and Ozawa 2003). The relations that make up industry agglomerations stretch across multiple geographical scales: local; regional; national and international (Phelps et al. 2015). Some externalities appear to be more locally bounded than others. Such insights allow for a reinterpretation of the existence of multiple industrial concentrations (of the same sector) within a single country. Individual industrial concentrations (in the same sector) may benefit from shared agglomeration economies, available at the national level, in addition to more locally or regionally bounded externalities.

The industrial concentrations observed in this article undoubtedly include a range of forms of industrial agglomeration involving different combinations of external economies available at different geographical scales. The pharmaceutical industry in Ireland can serve to illustrate some of these ideas. The spatial configuration of the industry is characterized by a high level of 
concentration, involving three substantial concentrations (in Cork, Dublin and Waterford) although pharmaceutical plants are operating in several other locations in the country. Detailed qualitative research on the Cork concentration (Van Egeraat and Curran 2014), showed that the pharmaceutical companies within that concentration utilized very few raw material input suppliers, even at the national level, supporting the idea of highly mobile pecuniary externalities (Phelps et al. 2015). The Cork-based pharmaceutical firms did benefit from proximity to a grouping of engineering companies. However, pharmaceutical firms in other parts of the country enjoyed the same level of benefit from these engineering companies, suggesting that this agglomeration advantage is available at the national level, rather than the local or regional level. The study found very little evidence of genuine technological spillovers, operating via untraded interdependencies - involved in the social network model of agglomeration distinguished by Gordon and McCann (2000). Cork-based pharmaceutical firms did benefit from labour market economies, some elements of which were locally bounded while other elements were available at the national scale. The situation has most in common with Gordon and McCann's classic model of pure agglomeration. It also illustrates the multiscalar nature of the external economies, relating individual concentrations (and plants outside these concentrations).

To take another example, the spatial configuration of the financial services sector is characterized by a single substantial concentration in Dublin (Table 3). The initial cause for this level of concentration was related to government policy, making fiscal incentives to financial companies conditional on their location in the demarcated International Financial Services Centre (IFSC). Initially, this industrial concentration had much in common with the modern-day enclave as conceptualized by Phelps et al. (2015). It was a physically, administratively and legally bounded territory characterized by high specialization in one activity and weak integration into the local economy - not generating localization economies related to the specialization. However, since its inception in 1989, the particular concentration has grown and evolved. Although we have, as yet, limited insight into the level of technological externalities, substantial labour market economies are currently available, mainly operating at the local scale. The regime that made incentives conditional to a location in the IFSC was abandoned more than 15 years ago. However, although some companies have since relocated (selected) activities, the IFSC continuous to grow and remains the single substantial concentration in the country (Reddan 2008). The situation now most closely relates to Gordon and McCann's classic model of pure agglomeration, but compared to the pharmaceutical sector, the processes are far more locally bounded.

The concentration index presented in this article improves our ability to identify substantial industrial concentrations. Industrial concentrations may be suggestive of the existence of agglomeration economies and beneficial clustering processes with which industrial policy may engage. However, industrial policy will require more detailed sectoral research as to the drivers of geographical industrial concentration, agglomeration processes, the role of the different external economies, and their multiscalar nature.

\section{References}

Ariba G (2001) The role of spatial effects in the empirical analysis of regional concentration. Journal of Geographical Systems 3: 271-281

Asheim GM (2005) The geography of innovation: Regional innovation systems. In: Fagerberg J, Mowery D, Nelson R (eds) The Oxford handbook of innovation. Oxford University Press, Oxford

Asheim B, Boschma R, Cooke P (2011) Constructing regional advantage: platform policies based on related variety and differentiated knowledge bases. Regional Studies 45(7): 893-904

Bickenbach F, Bode E, Krieger-Boden C (2013) Closing the gap between absolute and relative measures of localization, concentration or specialization. Papers in Regional Science 92: 465-479 
Brown RD (2010) Agglomeration economies: Where do they come from and to whom do they flow? In: Bathelt H, Feldman M, Kogler D (eds) Beyond territory: Dynamic geographies of knowledge creation and innovation. Routledge, Abingdon

Boschma R, Fornahl D (2011) Cluster evolution and a roadmap for future research. Regional Studies 45: 1295-1299

Brusco S (1989) A policy for industrial districts. In: Goodman E, Banford J (eds) Small firms in industrial districts in Italy. Routledge, London

Campos C (2012) The geographical concentration of industries. Office for National Statistics, London, Newport

Chesbrough H (2003) Open innovation. Harvard Business School Press, Boston, MA

Curran D, Van Egeraat C (2014) Linking subsidiary evolution and territorial development. Paper presented at the Geography of Innovation Conference. Utrecht, 23-25 January 2014

De Propris L (2005) Mapping local production systems in the UK: Methodology and application. Regional Studies 39: 197-211

Devereux M, Griffith R, Simpson H (2004) The geographic distribution of production activity in the UK. Regional Science and Urban Economics 34: 533-564

Duranton G (1999) Distance, land and proximity: Economic analysis and the evolution of cities. Environment and Planning A 31: 2169-2188

Duranton G, Overman H (2005) Testing for localization using micro-geographic data. Review of Economic Studies 72: 1077-1106

Ellison G, Glaeser E (1997) Geographic concentration in US manufacturing industries: A dartboard approach. Journal of Political Economy 105: 889-927

Flegg A, Webber C (1997) On the appropriate use of location quotients in generating regional input-output tables: Reply. Regional Studies 31: 795-805

Frenken K, Van Oort F, Verburg T (2007) Related variety, unrelated variety and regional economic growth. Regional Studies 41: 685-697

Giblin M (2008) Inward foreign investment and the clustering process: The case of the medical technology sector in Ireland. Working Paper Centre for Innovation \& Structural Change. National University of Ireland, Galway

Gordon I, McCann P (2000) Industrial clusters: Complexes, agglomeration and/or social networks. Urban Studies 37: 513-532

Hoover E (1937) Location theory and the shoe and leather industry. Harvard University Press, Cambridge, MA

Krugman P (1991) Geography and trade. Leuven University Press/The MIT Press, Leuven/ Cambridge, MA

Lafourcade M, Mion G (2007) Concentration, agglomeration and the size of plants. Regional Science and Urban Economics 37: 46-68

Lazzeretti L, Boix R, Capone F (2008) Do creative industries cluster? Mapping creative local production systems in Italy and Spain. Industry and Innovation 15: 549-567

Lever W (1972) Industrial movement, spatial association and functional linkages. Regional Studies 6: 371-383

Malerba F (2003) Sectoral systems: How and why innovation differs across sectors. In: Fagerberg J, Mowery D, Nelson R (eds) Handbook of innovation. Oxford University Press, Oxford

Malmberg A (1996) Industrial geography: Agglomeration and local milieu. Progress in Human Geography 20: 392-403

Malmberg A, Maskell P (1997) Towards an explanation of regional specialization and industry agglomeration. European Planning Studies 5: 25-41

Malmberg A, Malmberg B, Lundquist P (2000) Agglomeration and firm performance: Economies of scale, localisation and urbanisation among Swedish export firms. Environment and Planning A 32: 305-321

Malmberg A, Maskell P (2002) The elusive concept of localization economies: Towards a knowledge-based theory of spatial clustering. Environment and Planning A 34: 429-449

Markusen A (1996) Sticky places in slippery space: A typology of industrial districts. Economic Geography 72: 293-313

Marshall A (1898) Principles of economics (4th edn). Macmillan, London

Marshall A (1919) Industry and trade. Macmillan, London

Marshall A (1930) The pure theory of domestic values. London School of Economic and Political Science, London

Marcon E, Puech F (2003) Evaluating the geographic concentration of industries using distance-based methods. Journal of Economic Geography 3: 409-428

Martin R (1999) The new geographical turn in economics: Some critical reflections. Cambridge Journal of Economics 23: 65-91

Martin R (2012) Regional economic resilience, hysteresis and recessionary shocks. Journal of Economic Geography 12: $1-32$

Martin R, Sunley P (2003) Deconstructing clusters: Chaotic concept or policy panacea? Journal of Economic Geography 3: 5-35

Maurel F, Sedillot B (1999) A measure of the geographic concentration in French manufacturing industries. Regional Science and Urban Economics 29: 575-604

McCann P (1995) Rethinking the economics of location and agglomeration. Urban Studies 32: 563-577 
Menzel M, Henn S, Fornahl D (2010) Emerging clusters: a conceptual overview. In: Fornahl D, Henn S, Menzel M (eds) Emerging clusters: Theoretical, empirical and political perspectives on the initial stages of cluster formation. Edward Elgar, Cheltenham

Morgenroth E (2008) Economic integration and structural change: The case of Irish regions. In: Krieger-Boden C, Morgenroth E, Petrakos G (eds) The impact of European integration on regional structural change and cohesion. Routledge, London

Morgenroth E (2009) Exploring the economic geography of Ireland. Journal of the Statistical and Social Inquiry Society of Ireland 38: 42-69

O’Donaghue D, Gleave B (2004) A note on methods for measuring industrial agglomeration. Regional Studies 38: 419-427

Openshaw S (1983) The modifiable areal unit problem. Geo Books, Norwick

Orsenigo L (2006) Clusters and clustering in biotechnology: Stylised facts, issues and theories. In: Braunerhjelm P, Feldman M (eds) Cluster genesis. Oxford University Press, Oxford

Parr J (2002) Agglomeration economies: Ambiguities and confusions. Environment and Planning A 34: 717-731

Perry M (2005) Business clusters in the south: A critical appraisal from Indonesian evidence. Singapore Journal of Tropical Geography 26: 227-243

Phelps N (1992) External economies, agglomeration and flexible accumulation. Transactions of the Institute of British Geographers 17: 35-46

Phelps N (2004) Clusters, dispersion and the spaces in between: For an economic geography of the banal. Urban Studies 41: 971-989

Phelps N, Atienza M, Arias M (2015) Encore for the enclave: The changing nature of the industry enclave with illustrations from the mining industry in Chile. Economic Geography 91: 119-146

Phelps N, Ozawa T (2003) Contrasts in agglomeration: Proto-industrial, industrial and post-industrial forms compared. Progress in Human Geography 27: 583-604

Porter M (1990) The competitive advantage of nations. The Macmillan Press, Basingstoke, Hampshire

Prothero R (2012) Industrial specialisation in local areas. Office for National Statistics, London and Newport

Reddan F (2008) Ireland's IFSC: A story of global financial success. Mercier Press, Cork

Sweeney S, Feser E (1998) Plant size and clustering of manufacturing activity. Geographical Analysis 30: 45-64

Van Egeraat C, Curran D (2014) Spatial concentration in the Irish pharmaceutical industry: The role of spatial planning and agglomeration economies. Tijdschrift voor Economische en Sociale Geografie 104: 338-358

Van Egeraat C, Curran D (2013) Linking subsidiary evolution and territorial development. Paper presented at RSA conference on The Changing Role of Inward Investment and Regional Development: The Branch Plant Economy Re-Visited. Glasgow, 13 December 2012 